\title{
Discoloration of different esthetic restorative materials: A spectrophotometric evaluation
}

\author{
Matteo Ceci $^{1}$, Matteo Viola ${ }^{1}$, Davide Rattalino ${ }^{1}$, Riccardo Beltrami ${ }^{1}$, Marco Colombo ${ }^{1}$, \\ Claudio Poggio ${ }^{1}$
}

Correspondence: Dr. Claudio Poggio

Email: claudio.poggio@unipv.it
'Department of Clinical-Surgical, Diagnostic and Pediatric Sciences - Section of Dentistry, University of Pavia, Pavia, Italy

\section{ABSTRACT}

Objective: A crucial property of esthetic restorative materials is their long-term color stability. The aim of this in vitro study was to evaluate the color stability of esthetic restorative materials (one microfilled flowable composite, one nanofilled composite, one nanoybrid composite, one microfilled composite, and one nanoybrid ormocer-based composite) after surface roughening with cola and exposure to different staining solutions (coffee and red wine). Materials and Methods: All materials were polymerized into silicone rubber rings $(2 \mathrm{~mm} \times 6 \mathrm{~mm} \times 8 \mathrm{~mm})$ to obtain 150 specimens identical in size. Seventy-five specimens of Group A were first exposed to cola for $24 \mathrm{~h}$, and then samples were immersed in coffee or red wine over a 28-day test period. A colorimetric evaluation, according to the CIE L*a*b* system, was performed at 7, 14, 21, 28 days. Shapiro-Wilk test and Kruskal-Wallis analysis of variance were applied to assess significant differences among restorative materials. Means were compared with Scheffe's multiple comparison test at the 0.05 level of significance. Results: Specimens of Group A showed higher variations when compared with Group B's specimens $(P<0.05)$. After 28 days, the immersion protocols caused a clinically perceivable color change for all materials tested $(P<0.05)$. Ceram $\cdot \mathrm{X}$ Universal and Admira Fusion showed the lowest $\Delta \mathrm{E}$ variations $(P<0.05)$. Conclusions: Staining beverages caused significant discolorations for all the materials tested. The first exposure to cola enhanced the subsequent staining with coffee or red wine. Nanohybrid composites reported the lowest color variations.

Key words: CIE Lab, composite resins, discoloration

\section{INTRODUCTION}

Although improvements in esthetic restorative materials have been achieved during recent years, discoloration represents a significant problem for direct tooth-colored restorations. Various studies reported the overtime color change of light-cured composite resins due to extrinsic or intrinsic discoloration. ${ }^{[1]}$ Changes in color can be the result of intrinsic discoloration due to physicochemical

\begin{tabular}{|l|l|}
\hline \multicolumn{2}{|c|}{ Access this article online } \\
\hline Quick Response Code: \\
\hline
\end{tabular}

reactions in the deep portions of the restoration or the result of extrinsic discoloration due to accumulation of plaque and stains. ${ }^{[2]}$ Changes in color depend on several factors, such as the staining agent, the surface roughness, contact time with or immersion in coloring environments, and the type of composite resin used. ${ }^{[3-5]}$ Previous studies on color stability have shown that beverages, such as coffee, tea, red wine,

This is an open access article distributed under the terms of the Creative Commons Attribution-NonCommercial-ShareAlike 3.0 License, which allows others to remix, tweak, and build upon the work non-commercially, as long as the author is credited and the new creations are licensed under the identical terms.

For reprints contact: reprints@medknow.com

How to cite this article: Ceci M, Viola M, Rattalino $D$, Beltrami $R$, Colombo M, Poggio C. Discoloration of different esthetic restorative materials: A spectrophotometric evaluation. Eur J Dent 2017;11:149-56. DOI: 10.4103/ejd.ejd_313_16 
and cola can cause staining of composite resins to varying degrees. ${ }^{[3,6]}$

The structure of the resin matrix and characteristics of the filler particles directly affect the susceptibility to extrinsic staining. ${ }^{[7]}$ The staining susceptibility may be explained by the nature of the resin matrix and also may be correlated with the dimension of the filler particles. ${ }^{[8]}$ The affinity of the resin matrix for stains is modulated by its conversion rate and its chemical characteristics, water sorption rate being particularly important. ${ }^{[9]}$

Different classifications of composite resins according to various characteristics, such as size, content, and filler type, and the physical and mechanical properties of the materials have been proposed. ${ }^{[10]}$ Microfillers are particles that are smaller than $1 \mu$ while nanofillers are particles that are smaller than $0.1 \mu$. Most of the microfilled composites use particles that vary between 0.4 and $0.2 \mu$, while nanofilled composites are those that contain filler particles no larger than $0.1 \mu$ (more generally $0.04-0.05 \mu$ ). ${ }^{[11]} \mathrm{A}$ nanohybrid is a hybrid resin composite with nanofiller in a prepolymerized filler form. Microfilled flowable composites are formulated with a range of particle sizes between 1 and $2 \mu$ and the amount of filler is reduced (in the range of $50 \%$ by weight). ${ }^{[11]}$ The ormocer matrix is a polymer even before light curing. It consists of ceramic polysiloxane, which has low shrinkage as against the organic dimethacrylate monomer matrix seen in composites. ${ }^{[12]}$

A direct correlation between the in vitro and in vivo performances of an adhesive restorative system can hardly be made. This is because the three-dimensional configuration of a prepared tooth is inherently different from the flat surfaces used to test adhesive materials in vitro. In addition, the bonded interface is subjected to different stresses and more challenging situations in an in vivo model. Therefore, few studies have evaluated the in vivo color stability of the materials selected for this study. A study by Lawson et al. reported similar clinical color match after 2 years of service between microfilled flowable and conventional composites. ${ }^{[13]}$ In a 4-year clinical evaluation by Schirrmeister $\mathrm{et}$ al., Ceram 'X demonstrated acceptable marginal discoloration. ${ }^{[14]}$ Finally, Filtek Supreme XT and Gradia Direct posterior showed acceptable clinical performance and color stability after 5-year and 3-year clinical evaluations, respectively. ${ }^{[15,16]}$

Only limited information is available on the color stability of ormocer-type organoceramics. We

150 therefore designed an in vitro study to analyze ormocer discoloration, comparing it with different types of commonly used composites (flowable, nanofilled, microfilled, and nanohybrid ones). Recent studies demonstrated that acidic beverages, such as soft drinks (orange juice, and cola) or ethanol (whisky), can produce erosion of resin composites. ${ }^{[17]}$ Roughening of the surface caused by wear and chemical degradation may also affect the gloss and consequently increase extrinsic staining. ${ }^{[18]}$

Discoloration can be assessed visually and using instrumental techniques. Instrumental techniques eliminate the subjective interpretation inherent in a visual color comparison. Therefore, spectrophotometers and colorimeters are widely used tools to detect the color changes in dental restorative materials. ${ }^{[19]}$ Recent studies have shown that $\Delta \mathrm{E}$ threshold perceptibility and acceptability of 1.2 and 2.7, respectively, in dentists, evaluated on ceramics samples. Significant differences were observed among the different professional groups which participated in the study. ${ }^{[20]}$ However, it is currently accepted that color differences of $\Delta \mathrm{E}<1.0$ are imperceptible to the human eye while values of $\Delta \mathrm{E}>3.3$ are regarded as clinically unacceptable. ${ }^{[21]}$

The aim of this in vitro study was to evaluate and compare the color stability of different esthetic restorative materials (one microfilled flowable composite, one nanofilled composite, one nanoybrid composite, one microfilled composite, and one nanoybrid ormocer-based composite) after surface roughening with cola and exposure to different staining solutions (coffee and red wine). The null hypothesis is that esthetic restorative materials do not change color when staining agents are routinely applied.

\section{MATERIALS AND METHODS}

\section{Specimens' preparation}

One microfilled flowable composite (Gradia Direct Flo), one nanofilled composite (Filtek Supreme XTE), one nanohybrid composite (Ceram $\times X$ Universal), one microfilled composite (Gradia Direct), and one nanohybrid Ormocer-based composite (Admira Fusion) were evaluated in this study [Table 1]. For each brand, the A3 Vita shade was selected. All materials were polymerized according to manufacturers' instructions into silicone rubber rings (height $2 \mathrm{~mm}$; internal diameter $6 \mathrm{~mm}$; external diameter $8 \mathrm{~mm}$ ) to obtain specimens identical in size. Cavities of these rings 
were slightly overfilled with material, covered with mylar strip (Henry Schein, Melville, NY, USA), and pressed between glass plates and polymerized for 40 s on each side using a curing unit (Celalux II, Voco, Cuxhaven, Germany). One light polymerization mode was used for each material - standard: $1000 \mathrm{~mW} / \mathrm{cm}^{2}$ for $40 \mathrm{~s}$. The intensity of the light was verified with a radiometer (SDS Kerr, Orange, CA, USA). The light was placed perpendicular to the specimen surface, at distance of $1.5 \mathrm{~mm}$. The upper surface of each specimen was then polished with fine and superfine polishing disks (Sof-Lex Pop On; 3M ESPE, St. Paul, $\mathrm{MN}$, USA) to simulate clinical conditions. Thirty cylindrical specimens of each material were prepared in this manner, for a total of 150 specimens. After polymerization and during the experimentation, the specimens were stored in distilled water at $37^{\circ} \mathrm{C}$.

\section{Staining process}

Two test groups were obtained:

1. Group A: 75 specimens were previously immersed in $50 \mathrm{~mL}$ of soft drink (Coca Cola, Italy) for $24 \mathrm{~h}$

2. Group B: 75 specimens were immersed in physiological solution for $24 \mathrm{~h}$.

After the first immersion in soft drink or physiological solution, all specimens were then immersed in $50 \mathrm{~mL}$ of coffee (Nescafe Classic, Nestle, Switzerland) or in $50 \mathrm{~mL}$ of red wine (Bonarda Tenuta Casa Re, Montecalvo Versiggia, Italy) or in $50 \mathrm{~mL}$ physiological solution (control samples). Solutions were changed daily and put in vials with cover that prevent evaporation of staining solutions. For each composite material, five specimens were collected in each of the six subgroups as reported below:

1. Group A1: Immersion in soft drink and then in physiological solution

2. Group A2: Immersion in soft drink and then in wine

3. Group A3: Immersion in soft drink and then in coffee and similar for specimens included in Group B.

After staining period, the specimens were gently rinsed with distilled water, air-dried, and stored in distilled water at $37^{\circ} \mathrm{C}$. Flowchart [Figure 1] clarifies the specimens' staining process.

\section{Color measurements}

A colorimetric evaluation according to the CIE $\mathrm{L}^{*} \mathrm{a}^{*} \mathrm{~b}^{*}$ system was performed by the same operator at five experimental periods immediately after light-polymerization and at 7, 14, 21, 28 days of the staining process. The control samples have not been subjected to the staining process. Color of the specimens was measured with a spectrophotometer (SP820 $\lambda$; Techkon Gmbh, Konig-Stein, Germany) against a black background to simulate the absence of light in the mouth. $\mathrm{D}_{65}$ illuminant and CIE $10^{\circ}$ standard observer were used. Color measurements were performed under $0^{\circ} / 45^{\circ}$ illuminating/measuring geometry. All specimens were chromatically tested 4 times and

\section{Table 1: Esthetic restorative materials tested in this study}

\begin{tabular}{|c|c|c|c|c|}
\hline Material & Composition & Type & $\begin{array}{l}\text { Filler content } \\
\quad \%(w / w)\end{array}$ & Lot number \\
\hline $\begin{array}{l}\text { Gradia Direct Flo (GC } \\
\text { Corporation, Tokyo, Japan) }\end{array}$ & $\begin{array}{l}\text { Matrix: UDMA, dimethacrylate } \\
\text { component, stabilizer } \\
\text { Filler: Fluoroaluminosilicate glass silica powder }\end{array}$ & $\begin{array}{l}\text { Microfilled } \\
\text { flowable } \\
\text { composite }\end{array}$ & 52 & $140606 \mathrm{~A}$ \\
\hline $\begin{array}{l}\text { Filtek Supreme XTE (3M } \\
\text { ESPE, St Paul, MN, USA) }\end{array}$ & $\begin{array}{l}\text { Matrix: Bis-GMA, TEG-DMA, UDMA, bisphenol } \\
\text { A polyethylene glycol diether dimethacrylate } \\
\text { Filler: Silica nanofillers }(5-75 \mathrm{~nm}) \text { zirconia/ } \\
\text { silica nanoclusters }(0.6-1.4 \mu \mathrm{m})\end{array}$ & $\begin{array}{l}\text { Nanofilled } \\
\text { composite }\end{array}$ & 78.5 & N595296 \\
\hline $\begin{array}{l}\text { Ceram X Universal } \\
\text { (Dentsply De Trey, } \\
\text { Konstanz, Germany) }\end{array}$ & $\begin{array}{l}\text { Matrix: Methacrylate modified polysiloxane, } \\
\text { dimethacrylate resin, fluorescent pigment, } \\
\text { UV stabilizer, stabilizer, camphorquinone, } \\
\text { ethyl 4-(dimethylamino) benzoate, iron } \\
\text { oxide pigments, titanium oxide pigments, } \\
\text { aluminum sulfo-silicate pigments } \\
\text { Filler: Barium-aluminum-borosilicate } \\
\text { glass (1.1-1.5 } \mu \mathrm{m}) \text {, methacrylate functionalized } \\
\text { silicon dioxide nanofiller }(10 \mathrm{~nm})\end{array}$ & $\begin{array}{l}\text { Nanohybrid } \\
\text { composite with } \\
\text { prepolymerized } \\
\text { fillers }\end{array}$ & 76 & 1407000927 \\
\hline $\begin{array}{l}\text { Gradia Direct (GC } \\
\text { Corporation, Tokyo, Japan) }\end{array}$ & $\begin{array}{l}\text { Matrix: UDMA, dimethacrylate camphorquinone } \\
\text { Filler: Fluoroaluminosilicate glass silica powder }\end{array}$ & $\begin{array}{l}\text { Microfilled } \\
\text { composite }\end{array}$ & 73 & 140127A \\
\hline $\begin{array}{l}\text { Admira Fusion (Voco, } \\
\text { Cuxhaven, Germany) }\end{array}$ & $\begin{array}{l}\text { Matrix: Resin Ormocer } \\
\text { Filler: Silicon oxide nano filler, glass ceramics } \\
\text { filler }(1 \mu \mathrm{m})\end{array}$ & $\begin{array}{l}\text { Nanohybrid } \\
\text { Ormocer-based } \\
\text { composite }\end{array}$ & 84 & 1508065 \\
\hline
\end{tabular}


the average values were calculated; then, each color parameter for each specimens of the same shade was averaged. The CIE $1976 \mathrm{~L}^{*} \mathrm{a}^{*} \mathrm{~b}$ * color system is used for the determination of color differences. ${ }^{\left[{ }^{[1]}\right.}$ The total color differences $\left(\Delta \mathrm{Eab}^{*}\right)$ were calculated as follows:

$\Delta \mathrm{E}_{\mathrm{ab}}=\left(\Delta \mathrm{L}^{2}+\Delta \mathrm{a}^{2}+\Delta \mathrm{b}^{2}\right)^{1 / 2}$

Where $L^{*}$ is lightness, $a^{*}$ is green-red component $\left(-a^{*}=\right.$ green; $+a^{*}=$ red $)$, and $b^{*}$ is blue-yellow component $\left(-b^{*}=\right.$ blue; $+b^{*}=$ yellow $)$. A value of $\Delta \mathrm{Eab}^{*}<3.3$ was considered clinically acceptable in the present study..$^{[1,22,23]}$ The color measurements of the experimental groups were compared with those of the control group.

\section{Statistical analysis}

Statistical analysis was performed using computer software (Stata 12.0, Stata Corp., College Station, TX, USA). Descriptive statistics including the mean, standard deviation, median, and minimum and maximum values were calculated for each color coordinate for all the groups. By applying the formula, $\Delta \mathrm{E}_{\mathrm{ab}}=\left(\Delta \mathrm{L}^{2}+\Delta \mathrm{a}^{2}+\Delta \mathrm{b}^{2}\right)^{1 / 2}$, it was possible to calculate $\Delta \mathrm{E}$ and to compare the values before and after the staining immersion protocols. The distributions were assessed and found to be not normal (Shapiro-Wilk Test). Nonparametric Kruskal-Wallis one-way analysis of variance (ANOVA) was performed with the differences in color $\left(\Delta \mathrm{E}^{*} \mathrm{ab}\right)$ and three color coordinates $\left(\mathrm{CIE} \mathrm{L}^{*}\right.$, CIE $a^{*}$, and CIE $\left.b^{*}\right)$ between different immersion protocols in the specimen conditions such as before staining and after staining at the significance level of 0.05 . Changes in color coordinates were calculated as "color coordinate of stained surfaces." Means were compared with Scheffe's multiple comparison test at the 0.05 level of significance.

\section{RESULTS}

On the basis of one-way Kruskal-Wallis ANOVA, the first immersion in soft drink influenced all materials by changing significantly color coordinate CIE $\mathrm{L}^{*}(P<0.05)$ and consequently $\Delta \mathrm{E}$ as reported in Table 2 and Figures 1,2. Materials immersed in physiological solution did not showed minimal significant changes in each color coordinate $(P<0.05)$, thus providing $\Delta \mathrm{E}$ $>3.3$ even after 7 days. Immersions in coffee and wine caused significant variations for each color coordinate both in Group A and Group B $(P<0.05)$. Specimens of Group A showed higher color coordinate variations when compared with Group B's specimens $(P<0.05)$, thus showing $\triangle \mathrm{E}$ values significantly higher even after 7 days $(P<0.05)$. After 28 days, the immersion protocols caused a perceivable variation in color for

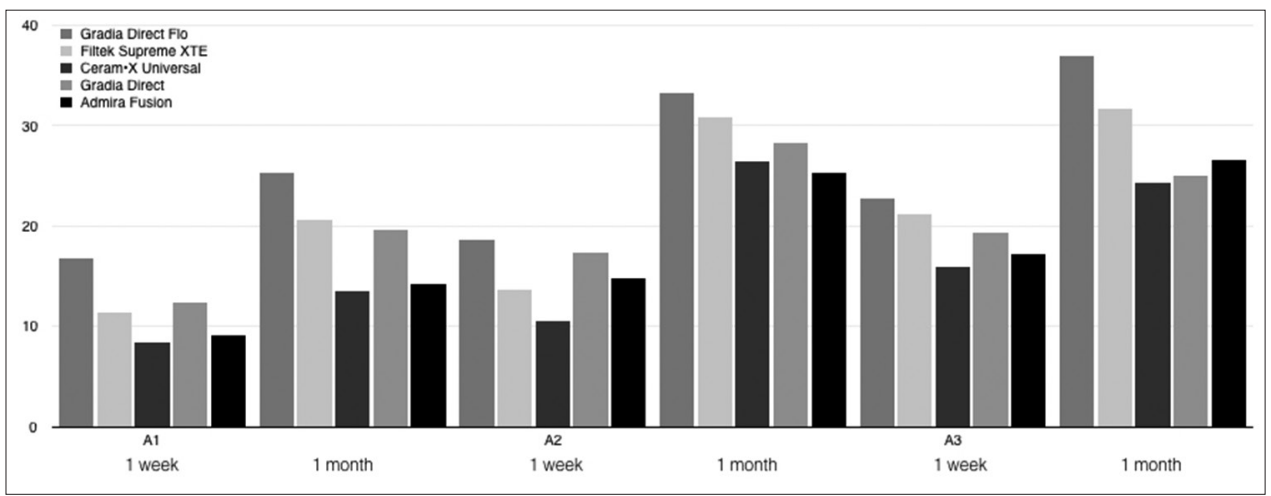

Figure 1: Results obtained in groups A by the different esthetic restorative materials tested

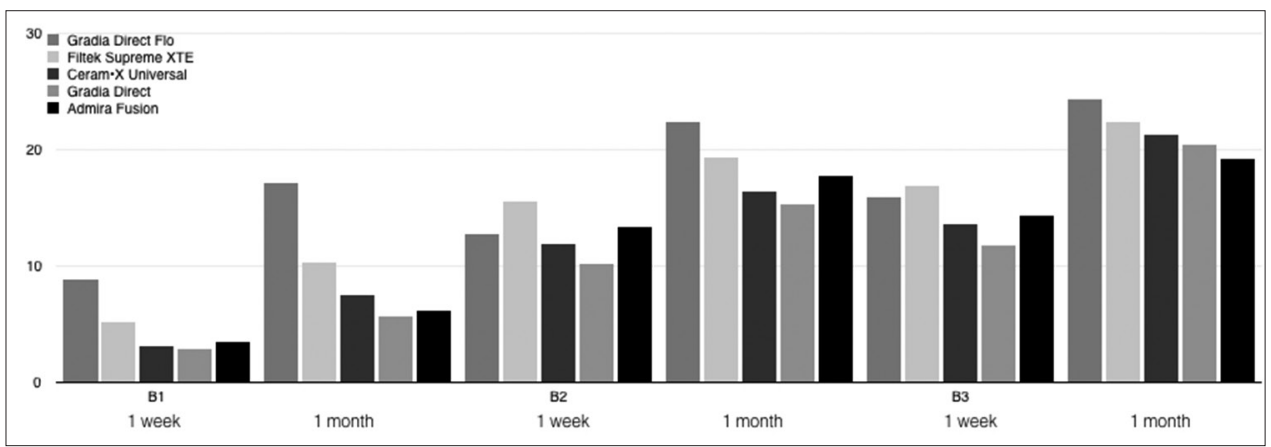

Figure 2: Results obtained in groups B by the different esthetic restorative materials tested 


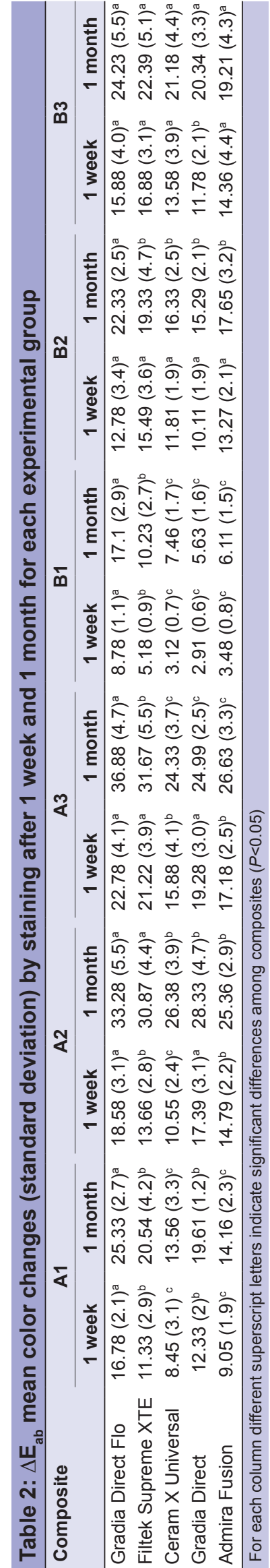

all materials tested in Group A as showed in Table 2. Ceram 'X Universal, Gradia Direct, and Admira Fusion showed the lowest $\Delta \mathrm{E}$ variations both for specimens assigned to Group A both for specimens assigned to Group B. Gradia Direct Flo showed the highest variation for each color coordinate in each of the two experimental groups $(P<0.05)$, except when immersed in physiological solution. The highest color change for all materials was registered when specimens were immersed in coffee $(P<0.05)$.

\section{DISCUSSION}

The null hypothesis of the study that the esthetic restorative materials tested do not present over time discoloration after surface roughening with cola and staining was rejected. In fact, after 28 days, the staining protocols caused perceivable color variations for all the materials tested. Furthermore, significant differences in color stability among the different materials were reported.

The choice of a single color tone may be a limitation of this study; however, in accordance with previous studies, only the A3 Vita shade was selected for each type of the composites tested in this study. ${ }^{[24]}$ To assess color change of dental materials, visually and/or specific instruments have been proposed. ${ }^{[24]}$ The methodology used in the present study was in accordance with previous researches that used spectrophotometry and the CIE L*a*b* coordinate system, which is a widely used tool for dental purposes. ${ }^{[22]}$ Various studies reported the advantages of using the CIE $L^{*} a^{*} b^{*}$ coordinate system, such as its repeatability, sensitivity, and objectivity. This technique is well suited for the determination of small color variations $(\Delta \mathrm{E}) \cdot{ }^{[22]}$ Several authors have reported that $\Delta \mathrm{E}$ values ranging from 1 to 3 are perceptible to the naked eye and $\Delta \mathrm{E}$ values $>3.3$ are clinically unacceptable. ${ }^{[23,25]}$

In this study, a long-term staining protocol of 28 days was performed. This time of exposure should simulate around 2 years of clinical exposure to the staining agents ( $24 \mathrm{~h}$ in vitro corresponds to about 1 month in vivo), which is considered sufficient for a long-term staining susceptibility evaluation. ${ }^{[26]}$

Not only coffee, cola, or red wine ${ }^{[27]}$ but also tea, fruit juices, and other common food dyes could significantly affect the color of composite resin materials. ${ }^{[6,28]}$ In this study, immersion in physiological solution did not cause significant color changes, with $\Delta \mathrm{E}<3.3$ even after 28 days. Contrariwise both 
immersions in coffee and wine caused significant color variations. The adsorption and/or absorption of colorants may explain the discoloration produced by coffee. The absorption and penetration of colorants into the organic phase of materials were probably due to compatibility of the polymer phase with the yellow colorants of coffee. ${ }^{[29]}$ Furthermore, tannins, contained in red wine, possess a strong discoloration capacity. ${ }^{[30]}$ In our study, coffee caused higher color changes for all the materials tested if compared to red wine. This is in accordance with other studies which demonstrated that certain substances (e.g., coffee) may cause more severe staining than others. ${ }^{[2,7]}$

In this study, considering the specimens of Group A, the first immersion in cola influenced the staining susceptibility of all materials by changing significantly the color coordinates. Although various studies reported that cola drinks do not strongly affect color stability of composites; ${ }^{[31]}$ in this study, the first exposure to coke enhanced the subsequent discoloration by coffee and red wine. This finding may be explained by the presence of phosphoric acid in coke. Various authors recently reported that the exposure to acidic or alcoholic drinks altered in different degrees the surface roughness of resin composites. ${ }^{[17]}$ The sorption of acid or alcohol molecules into the resin matrix could enhance the staining process, softening the composite resin surface. ${ }^{[30]}$ Acids may affect the surface smoothness and consequently increase extrinsic discoloration. ${ }^{[18]}$

The staining susceptibility of esthetic restorative materials is influenced by various components. ${ }^{[32]}$ Three types of discolorations are usually reported (1) external discoloration due to the accumulation of plaque and surface stains (extrinsic stain), (2) surface or subsurface color variations consisting of superficial degradation or slight penetration and reaction of colorants within the superficial layer of resins (absorption), and (3) body or intrinsic discoloration due to physicochemical reactions in the deepest layer of the material. ${ }^{[32]}$ Water is the carrier for pigments to penetrate into the resin matrix and Dietschi et al. showed that staining susceptibility tends to correspond with water sorption rate. ${ }^{[32]}$ The glass filler particles do not absorb water. Therefore, greater amount of resin matrix results in greater water sorption. It has been reported that composite resins with a lower amount of inorganic fillers presented more color change because the greater resin matrix volume allows greater water sorption. ${ }^{[33]}$ These considerations are supported by the results obtained in this study by Gradia Direct Flo. Gradia Direct Flo reported the highest discoloration values in both experimental groups. This higher staining susceptibility is explained by the lower filler content ( $52 \% \mathrm{w} / \mathrm{w}$ ) of Gradia Direct Flo microfilled flowable composite if compared to the other tested materials.

Resin monomers are the foremost common chemical components of composite restorative materials. Both acrylates and methacrylates monomers are vulnerable to water degradation (hydrolysis) of their ester groups. ${ }^{[34]}$ According to Sideridou et al., triethylene glycol dimethacrylate (TEGDMA) has the highest water sorption capability, followed by BisGMA and by urethane dimethacrylate. ${ }^{[35]}$ In the present study, these differences were not clearly evident. Although they presented different type of monomer in their resin matrix, all the composites tested presented in fact significant color alteration after 28 days. In any case, Filtek Supreme XTE, which contains the TEGDMA monomer, showed the highest $\Delta \mathrm{E}$ value at all at 28 days.

Recently, manufacturers are producing composites with smaller filler particles. The lower particle size and better distribution within the resin matrix produce smoother surfaces. ${ }^{[36]}$ Although some studies have shown that the small dimension of the particles of nanofilled composite resin permits low staining susceptibility; ${ }^{[37]}$ other researchers reported that increased particle size resulted in less color change due to a decrease in the proportion of organic filler matrix. ${ }^{[38]}$ Villalta et al. demonstrated that nanofilled composite resins absorb stains more easily than microfilled ones. ${ }^{[1]}$ Lee and Powers obtained similar results, concluding that the smoothest surfaces were not necessarily the most stain resistant, and staining ability was influenced by each composite monomer and filler composition. ${ }^{[2]}$ This study showed conflicting results. In fact, Filtek Supreme XTE nanofilled composite showed highest discoloration at each stage of the staining protocol when compared with a microfilled composite such as Gradia Direct. To date, no studies have compared the staining susceptibility of an ormocer-based composite with the novel Ceram 'X Universal nanohybrid composite. Ormocer materials contain inorganic-organic copolymers in addition to the inorganic silanated filler particles. To the polysiloxane chains in ormocer, polymerisable side chains are added to react during curing and form the setting matrix. These inorganic molecules explain the material's lower volumetric shrinkage. ${ }^{[39]}$ Recent studies reported some advantages of ormocer-based materials, including low shrinkage, high abrasion 
resistance, and biocompatibility. ${ }^{[12]}$ The staining susceptibility of ormocers has been also recently evaluated. ${ }^{[40]}$ The resin matrix of Ceram $X$ Universal is based on a significantly modified version of the polysiloxane comprising matrix from the original Ceram $\cdot X$ mono+/duo+. The resin matrix also contains highly dispersed, methacrylic polysiloxane nanoparticles, which are chemically similar to glass or ceramics. In this study, Ceram 'XUniversal and Admira Fusion showed similar results, thus demonstrating the lowest $\Delta \mathrm{E}$ variations with or without the first exposure to coke. These two different nanohybrid composite demonstrated lower staining susceptibility if compared to the other microfilled and nanofilled materials tested. Our results are in accordance with recent studies which reported higher discoloration for nanofilled composites compared to nanohybrid ones. ${ }^{[41,42]}$ Ayad showed for ormocer composites significantly lower color susceptibility if compared to nanofilled resins. ${ }^{[43]}$ Finally, a recent study by Ren et al. evaluated the overtime discoloration of Ceram $\times X$ Universal after thermocycling in typical staining beverages and the results reported lower discoloration for Ceram $\times X$ Universal if compared to nanofilled materials. ${ }^{[44]}$

\section{CONCLUSIONS}

Within the limitations of this in vitro study, it can be concluded that the immersion of specimens in staining beverages caused a significant color change in all types of tested composite resins. The first exposure to cola influenced the staining susceptibility of all materials, enhancing the subsequent staining with coffee or red wine. Coffee demonstrated a higher staining potential if compared to red wine. Finally, among the different materials tested, nanohybrid composites (Ceram 'X Universal and Admira Fusion) reported the lowest color variations.

\section{Financial support and sponsorship}

Nil.

\section{Conflicts of interest}

There are no conflicts of interest.

\section{REFERENCES}

1. Villalta P, Lu H, Okte Z, Garcia-Godoy F, Powers JM. Effects of staining and bleaching on color change of dental composite resins. J Prosthet Dent 2006;95:137-42.

2. Mundim FM, Garcia Lda F, Pires-de-Souza Fde C. Effect of staining solutions and repolishing on color stability of direct composites. J Appl Oral Sci 2010;18:249-54.

3. Bagheri R, Burrow MF, Tyas M. Influence of food-simulating solutions and surface finish on susceptibility to staining of aesthetic restorative materials. J Dent 2005;33:389-98.

4. Reis AF, Giannini M, Lovadino JR, Ambrosano GM. Effects of various finishing systems on the surface roughness and staining susceptibility of packable composite resins. Dent Mater 2003;19:12-8.

5. Omata Y, Uno S, Nakaoki Y, Tanaka T, Sano H, Yoshida S, et al. Staining of hybrid composites with coffee, oolong tea, or red wine. Dent Mater J 2006;25:125-31.

6. Soares-Geraldo D, Scaramucci T, Steagall-Jr W, Braga SR, Sobral MA. Interaction between staining and degradation of a composite resin in contact with colored foods. Braz Oral Res 2011;25:369-75.

7. Barutcigil Ç, Yildiz M. Intrinsic and extrinsic discoloration of dimethacrylate and silorane based composites. J Dent 2012;40 Suppl 1:e57-63.

8. Vichi A, Ferrari M, Davidson CL. Color and opacity variations in three different resin-based composite products after water aging. Dent Mater 2004;20:530-4.

9. de Gee AJ, ten Harkel-Hagenaar E, Davidson CL. Color dye for identification of incompletely cured composite resins. J Prosthet Dent 1984;52:626-31.

10. Senawongse P, Pongprueksa P. Surface roughness of nanofill and nanohybrid resin composites after polishing and brushing. J Esthet Restor Dent 2007;19:265-73.

11. Ferracane JL. Resin composite - State of the art. Dent Mater 2011;27:29-38.

12. Kalra S, Singh A, Gupta M, Chadha V. Ormocer: An aesthetic direct restorative material; an in vitro study comparing the marginal sealing ability of organically modified ceramics and a hybrid composite using an ormocer-based bonding agent and a conventional fifth-generation bonding agent. Contemp Clin Dent 2012;3:48-53.

13. Lawson NC, Radhakrishnan R, Givan DA, Ramp LC, Burgess JO. Two-year randomized, controlled clinical trial of a flowable and conventional composite in class I restorations. Oper Dent 2015:40:594-602.

14. Schirrmeister JF, Huber K, Hellwig E, Hahn P. Four-year evaluation of a resin composite including nanofillers in posterior cavities. J Adhes Dent 2009;11:399-404.

15. Cetin AR, Unlu N, Cobanoglu N. A five-year clinical evaluation of direct nanofilled and indirect composite resin restorations in posterior teeth. Oper Dent 2013;38:E1-11.

16. Palaniappan S, Elsen L, Lijnen I, Peumans M, Van Meerbeek B, Lambrechts P. Three-year randomised clinical trial to evaluate the clinical performance, quantitative and qualitative wear patterns of hybrid composite restorations. Clin Oral Investig 2010;14:441-58.

17. Poggio C, Dagna A, Chiesa M, Colombo M, Scribante A. Surface roughness of flowable resin composites eroded by acidic and alcoholic drinks. J Conserv Dent 2012;15:137-40.

18. Badra VV, Faraoni JJ, Ramos RP, Palma-Dibb RG. Influence of different beverages on the microhardness and surface roughness of resin composites. Oper Dent 2005;30:213-9.

19. Borges A, Caneppele T, Luz M, Pucci C, Torres C. Color stability of resin used for caries infiltration after exposure to different staining solutions. Oper Dent 2014;39:433-40.

20. Paravina RD, Ghinea R, Herrera LJ, Bona AD, Igiel C, Linninger M, et al. Color difference thresholds in dentistry. J Esthet Restor Dent 2015;27 Suppl 1:S1-9.

21. Schulze KA, Marshall SJ, Gansky SA, Marshall GW. Color stability and hardness in dental composites after accelerated aging. Dent Mater 2003;19:612-9.

22. Brook AH, Smith RN, Lath DJ. The clinical measurement of tooth colour and stain. Int Dent J 2007;57:324-30.

23. Noie F, O'Keefe KL, Powers JM. Color stability of resin cements after accelerated aging. Int J Prosthodont 1995;8:51-5.

24. Poggio C, Beltrami R, Scribante A, Colombo M, Chiesa M. Surface discoloration of composite resins: Effects of staining and bleaching. Dent Res J (Isfahan) 2012;9:567-73.

25. Lee YK, Powers JM. Discoloration of dental resin composites after immersion in a series of organic and chemical solutions. J Biomed Mater Res B Appl Biomater 2005;73:361-7.

26. Ertas E, Güler AU, Yücel AC, Köprülü H, Güler E. Color stability of resin composites after immersion in different drinks. Dent Mater J 2006;25:371-6.

27. Guler AU, Yilmaz F, Kulunk T, Guler E, Kurt S. Effects of different 
drinks on stainability of resin composite provisional restorative materials. J Prosthet Dent 2005;94:118-24.

28. Tunc ES, Bayrak S, Guler AU, Tuloglu N. The effects of children's drinks on the color stability of various restorative materials. J Clin Pediatr Dent 2009;34:147-50.

29. Um CM, Ruyter IE. Staining of resin-based veneering materials with coffee and tea. Quintessence Int 1991;22:377-86.

30. Catelan A, Briso AL, Sundfeld RH, Goiato MC, dos Santos PH. Color stability of sealed composite resin restorative materials after ultraviolet artificial aging and immersion in staining solutions. J Prosthet Dent 2011;105:236-41.

31. Aliping-McKenzie M, Linden RW, Nicholson JW. The effect of Coca-Cola and fruit juices on the surface hardness of glass-ionomers and 'compomers'. J Oral Rehabil 2004;31:1046-52.

32. Dietschi D, Campanile G, Holz J, Meyer JM. Comparison of the color stability of ten new-generation composites: An in vitro study. Dent Mater 1994;10:353-62.

33. Fontes ST, Fernández MR, de Moura CM, Meireles SS. Color stability of a nanofill composite: Effect of different immersion media. J Appl Oral Sci 2009;17:388-91.

34. Van Landuyt KL, Snauwaert J, De Munck J, Peumans M, Yoshida Y, Poitevin A, et al. Systematic review of the chemical composition of contemporary dental adhesives. Biomaterials 2007;28:3757-85.

35. Sideridou I, Tserki V, Papanastasiou G. Study of water sorption, solubility and modulus of elasticity of light-cured dimethacrylate-based dental resins. Biomaterials 2003;24:655-65.

36. Reis AF, Giannini M, Lovadino JR, dos Santos Dias CT. The effect of six polishing systems on the surface roughness of two packable resin-based composites. Am J Dent 2002;15:193-7.

37. Nasim I, Neelakantan P, Sujeer R, Subbarao CV. Color stability of microfilled, microhybrid and nanocomposite resins - An in vitro study. J Dent 2010;38 Suppl 2:e137-42.

38. Paravina RD, Roeder L, Lu H, Vogel K, Powers JM. Effect of finishing and polishing procedures on surface roughness, gloss and color of resin-based composites. Am J Dent 2004;17:262-6.

39. Bacchi A, Feitosa VP, da Silva Fonseca AS, Cavalcante LM, Silikas N, Schneider LF. Shrinkage, stress, and modulus of dimethacrylate, ormocer, and silorane composites. J Conserv Dent 2015;18:384-8.

40. Gregor L, Krejci I, Di Bella E, Feilzer AJ, Ardu S. Silorane, ormocer, methacrylate and compomer long-term staining susceptibility using $\Delta \mathrm{E}$ and $\Delta \mathrm{E} 00$ colour-difference formulas. Odontology 2016;104:305-9.

41. Farah RI, Elwi H. Spectrophotometric evaluation of color changes of bleach-shade resin-based composites after staining and bleaching. J Contemp Dent Pract 2014;15:587-94.

42. Malhotra N, Shenoy RP, Acharya S, Shenoy R, Mayya S. Effect of three indigenous food stains on resin-based, microhybrid-, and nanocomposites. J Esthet Restor Dent 2011;23:250-7.

43. Ayad NM. Susceptibility of restorative materials to staining by common beverages: An in vitro study. Eur J Esthet Dent 2007;2:236-47.

44. Ren YF, Feng L, Serban D, Malmstrom HS. Effects of common beverage colorants on color stability of dental composite resins: The utility of a thermocycling stain challenge model in vitro. J Dent 2012;40 Suppl 1:e48-56. 